\section{Paradoxical rise in blood pressure during propranolol treatment}

Common side effects of beta-blocking agents include nausea, vomiting, diarrhoea, ataxia, and psychosis. We record another, potentially lifethreatening reaction-namely, hypertension-which may be reversed by alpha-adrenergic-blocking agents.

\section{Patients, methods, and results}

With the informed consent of relatives 44 patients mainly with acute exacerbations of schizophrenic disorders, in the manic phase of manicdepressive illnesses, or with post-partum psychoses were given propranolol by mouth in rapidly increasing doses. All were taking part in an open trial of the effects of large doses of propranolol. ${ }^{12}$ Only two were aged over 45 and none had organic disease. For at least one week before the study all treatment was stopped. The effects of propranolol were monitored by measuring pulse rate and blood pressure every one to three hours.

Most patients received about $600 \mathrm{mg}$ propranolol the first day, the dose being increased by $400-800 \mathrm{mg}$ daily until the pulse fell to $58-64 / \mathrm{min}$, blood pressure falling to about $90 / 60 \mathrm{~mm} \mathrm{Hg}$. The largest individual doses ranged from 600 to $5000 \mathrm{mg}$ daily. When treatment was successful the symptoms improved with the reduction in pulse rate and blood pressure.

The common side effects occurred in a few patients, but eight developed an appreciable increase in blood pressure (table). This was not due to an "escape" from beta-adrenergic blockade because the pulse rate remained low (58-62/min). In most cases the increase was progressive over 3-24 hours, while in two it occurred abruptly, accompanied by other signs of crisis. Two patients developed hypertension when the pulse rate had fallen to about $60 / \mathrm{min}$, and in the others it occurred when the dosage was increased after a reduction had caused partial or complete release of the blockade.

Increase in blood pressure during propranolol treatment

\begin{tabular}{l|c|c|c|c}
\hline $\begin{array}{c}\text { Case } \\
\text { No }\end{array}$ & Sex & $\begin{array}{c}\text { Age } \\
\text { (years) }\end{array}$ & $\begin{array}{c}\text { Daily propranolol } \\
\text { dosage at time of } \\
\text { hypertension } \\
\text { (mg) }\end{array}$ & $\begin{array}{c}\text { Increase in } \\
\text { blood pressure } \\
\text { (mm Hg) }\end{array}$ \\
\hline $1^{*}$ & $\mathrm{~F}$ & 17 & 5000 & $90 / 60-260 / 170$ \\
2 & $\mathrm{M}$ & 20 & 1200 & $90 / 70-160 / 90$ \\
3 & $\mathrm{M}$ & 23 & 2400 & $90 / 60-170 / 100$ \\
$4^{*}$ & $\mathrm{M}$ & 22 & 1800 & $90 / 60-200 / 160$ \\
5 & $\mathrm{M}$ & 20 & 600 & $90 / 70-170 / 120$ \\
6 & $\mathrm{M}$ & 19 & 800 & $90 / 60-180 / 120$ \\
7 & $\mathrm{M}$ & 35 & 1000 & $90 / 60-160 / 90$ \\
8 & $\mathrm{~F}$ & 32 & 600 & $90 / 60-180 / 110$ \\
\hline
\end{tabular}

*These patients developed hypertensive crises.

During the hypertensive phase in those in whom the hypertension developed gradually the skin was pale, cold, and clammy and the patients exhibited pronounced tension and outburts of psychomotor unrest. In all cases the hypertension responded immediately to a single dose of phentolamine 15-30 $\mathrm{mg}$ intravenously, phenoxybenzamine $10-20 \mathrm{mg}$ daily for three or four days reducing the blood pressure to the previous low levels. With the reduction in blood pressure the other symptoms subsided. During the phenoxybenzamine treatment propranolol was continued.

In some cases the skin signs and symptoms of pronor nced tension and psychomotor unrest were noted as the blood pressure began to rise. In a few further cases in which these symptoms appeared phentolamine and phenoxybenzamine given together prevented the rise in blood pressı re despite continuing with the propranolol.

\section{Discussion}

Though propranolol is an antihypertensive agent, hypertensive crises may occur during its use in patients with phaochromocytoma. ${ }^{3}$ They are thought to be caused by an unopposed alpha-receptorconstrictor response to excessive catecholamine levels. Propranolo inhibits catecholamine release, and, interestingly, most episodes of hypertension in our series occurred when the propranolol dosage was increased after a previous reduction. Presumably the reduction caused an excessive release of catecholamines, which, when the dosage was increased, acted on unopposed alpha-adrenergic receptors. These phenomena, however, may have other explanations.
Until recently the paradoxical hypertensive response to betablockers could be regarded as specific for phaochromocytoma or psychosis. Then, however, a patient on methyldopa was reported to have become hypertensive when injected intravenously with propranolol, ${ }^{4}$ and in another report ${ }^{5}$ a hypertensive woman with insulindependent diabetes developed a hypertensive crisis after beginning treatment with propranolol. Thus the response may occur in any patient given beta-adrenergic-blocking agents when excessive amounts of catecholamines are released.

In view of the severity of the hypertension and the effectiveness of alpha-adrenergic-blocking agents treatment should be given immediately.

1 Atsmon, A, et al, Psychopharmacologia, 1972, 27, 249.

2 Steiner, M, et al, Psychiatria, Neurologia, Neurochirurgia, 1973, 76, 421.

${ }^{3}$ Prichard, B N C, and Ross, E J, American fournal of Cardiology, 1966, $18,394$.

4 Nies, A S, and Shand, D G, Clinical Pharmacology and Therapeutics, 1973, 14, 823.

${ }^{5}$ McMurtry, R J, Annals of Internal Medicine, 1974, 80, 669.

Department of Internal Medicine B, Beilinson Medical Centre, Sackler School of Medicine, University of Tel Aviv, Israel

I BLUM, MD, lecturer in internal medicine

A ATSMON, MD, PH D, associate professor of internal medicine

Geha Psychiatric Hospital, Sackler School of Medicine, University of Tel Aviv, Israel

M STEINER, MD, instructor in psychiatry (present address: Shalvata Psychiatric Hospital, Hod Hasharon, Israel)

$\mathrm{H}$ WYSENBEEK, MD, PH D, associate professor of psychiatry

\section{Monitoring muscle weakness in neonatal myasthenia gravis}

Neonatal myasthenia gravis is rare. ${ }^{1}$ We report a case and describe a simple method used to monitor the muscle weakness.

\section{Patient, method, and results}

The infant, a boy, was delivered by lower uterine segment caesarean section of a 26-year-old primigravida who had been diagnosed a year before as suffering from myasthenia gravis. This had progressed rapidly and was therefore classed as type 3 by the Osserman and Genkins classification. The infant's gestational age was 36 weeks; he weighed $2540 \mathrm{~g}$ and had an Apgar score of 9 at 1 minute and 9 at 5 minutes. His mouth was continuously open; there were few facial movements, and there was evident hypotonia. A poor feeder, he was described as being eager to suck but tired quickly. A positive edrophonium test confirmed the diagnosis of neonatal myasthenia gravis. He was treated with intramuscular neostigmine methylsulphate.

With a balloon (Dunlop Ltd) attached to a feeding tube which linked it to a micromanometer ( $250 \mathrm{~mm}$ WG, Furness Controls Ltd) which was in turn connected to a pen recorder (M8 Recorder Devices Ltd), the infant's sucking pressure was measured before a feed on several occasions. At 6 and 14 days of age the pressures were measured before and after an intravenous injection of $1 \mathrm{mg}$ of edrophonium chloride. Before starting the study the volume of the balloon which would accurately reflect any change in pressure was determined by experiment. ${ }^{3}$ Normal, healthy, full-term infants acted as controls.

The sucking pressures were recorded when the infant was 6 days old (see fig). A dramatic improvement after intravenous edrophonium chloride was evident. The mean $( \pm S D$ ) pre-feed sucking pressure for 20 full-term infants was $35 \pm 6 \mathrm{~cm} \mathrm{H} \mathrm{H}_{2} \mathrm{O}$. The infant's sucking pressure was monitored and a return to normal was used as a guide to stopping the neostigmine treatment. By the 14th day the sucking pressures before and after intravenous edrophonium chloride were the same. This finding correlated well with an electromyographic recording of the response to repetitive nerve stimulation, which nlso confirmed the absence of muscle weakness at that time. Drug treatmint was therefore stopped without ill effect. 